\title{
Sorption of Uranium Ions from Their Aqueous Solution by Resins Containing Nanomagnetite Particles
}

\author{
Mahmoud O. Abd El-Magied \\ Nuclear Materials Authority, P.O. Box 530, El Maadi, Cairo, Egypt \\ Correspondence should be addressed to Mahmoud O. Abd El-Magied; mahmoud_nma@yahoo.com
}

Received 15 November 2015; Accepted 26 January 2016

Academic Editor: Dmitry Murzin

Copyright ( 2016 Mahmoud O. Abd El-Magied. This is an open access article distributed under the Creative Commons Attribution License, which permits unrestricted use, distribution, and reproduction in any medium, provided the original work is properly cited.

\begin{abstract}
Magnetic amine resins composed of nanomagnetite $\left(\mathrm{Fe}_{3} \mathrm{O}_{4}\right)$ core and glycidyl methacrylate $(\mathrm{GMA}) / \mathrm{N}, \mathrm{N}^{\prime}$-methylenebisacrylamide (MBA) shell were prepared by suspension polymerization of glycidyl methacrylate with $\mathrm{N}, \mathrm{N}^{\prime}$-methylenebisacrylamide in the presence of nanomagnetite particles and immobilized with different amine ligands. These resins showed good magnetic properties and could be easily retrieved from their suspensions using an external magnetic field. Adsorption behaviors of uranium ions on the prepared resins were studied. Maximum sorption capacities of uranium ions on R-1 and R-2 were found to be 92 and $158 \mathrm{mg} / \mathrm{g}$. Uranium was extracted successfully from three granite samples collected from Gabal Gattar pluton, North Eastern Desert, Egypt. The studied resins showed good durability and regeneration using $\mathrm{HNO}_{3}$.
\end{abstract}

\section{Introduction}

Recently, synthesis, properties, and application of magnetic polymer beads in solving many environmental problems have received considerable attention. The magnetoresponsive polymeric beads benefit comes from the combination of their components features: magnetic particles and polymer $[1,2]$. Magnetic chelating resins are conveniently used to treat industrial wastewater and recover metal ions where they are easily collected and rapidly precipitated in a magnetic field that improves the operative technology of recovery and separation. Magnetic chelating resins are prepared by coating magnetic nano- or microiron particles or another ferromagnetic material with either an organic polymer or ion exchange resin by adsorption or by direct bonding; the size of beads can vary from hundred nanometers to few millimeters [3-6].

Synthesis of magnetic polymer beads can be achieved in three ways: (1) the magnetic particles are synthesized inside polymer matrix, (2) the polymer is synthesized in the presence of magnetic particles, and (3) the beads are prepared from preformed polymer and magnetic particles [6-10]. Magnetic core-polymer shell beads are usually prepared by three-dimensional polymerization of monomer together with cross-linker on the surface of magnetic particles. Nano- and micromagnetic particles are of great interest for many technological applications like separation of metal ions, medical applications, and oil industry [3-10].

$\mathrm{Fe}_{3} \mathrm{O}_{4}$-glycidyl methacrylate/iminodiacetic acid/styrene/ divinylbenzene resin was prepared and used in removal of $\mathrm{Cu}^{+2}, \mathrm{Cd}^{+2}$, and $\mathrm{Pb}^{+2}$ from aqueous solutions. The equilibrium adsorption capacities of the resin were $0.88,0.81$, and $0.78 \mathrm{mmol} / \mathrm{g}$ for $\mathrm{Cu}^{+2}, \mathrm{~Pb}^{+2}$, and $\mathrm{Cd}^{+2}$, respectively [3]. Magnetic poly(GMA) microspheres were prepared by polymerization of GMA in the presence of polyethylene glycol-coated magnetite nanoparticles. The microspheres were hydrolyzed and carboxyl groups introduced by oxidation with $\mathrm{KMnO}_{4}$ [4]. A magnetic chelating resin was obtained from polymerization of glycidyl methacrylate in the presence of divinylbenzene as a cross-linker and finely divided magnetic particles of $\mathrm{Co}_{3} \mathrm{O}_{4}$. The embedded metal oxide particles impart magnetic properties to the resin in addition to increasing the chelating active sites on the surface. The obtained resin was modified with amine functionality and evaluated towards the uptake of $\mathrm{Hg}^{+2}, \mathrm{Cu}^{+2}$, and $\mathrm{Ni}^{+2}$ from their aqueous solutions [5]. GMA/MBA resins modified by embedded iron oxide $\left(\mathrm{Fe}_{2} \mathrm{O}_{3}\right)$ were prepared. Amino and thiol functionalities were immobilized on the obtained resins 
for Ag adsorption. [6]. Glycidyl methacrylate resins were prepared in the presence and absence of iron oxide $\left(\mathrm{Fe}_{2} \mathrm{O}_{3}\right)$. The conducted resins were subsequently treated with ethylenediamine giving the corresponding amine-chelating resins. The uptake behavior of both resins towards $\mathrm{Cu}^{+2}$ ions in aqueous solutions using batch and column techniques was studied [7]. Magnetic chitosan resin was chemically modified by a polymeric Schiff's base cross-linker and used for mercury ${ }^{+2}$ uptake with capacity value of $2.8 \mathrm{mmol} / \mathrm{g}$ [8]. Schiff's base chitosan composites with magnetic properties were prepared through the reaction between chitosan and polymeric Schiff base of thiourea/glutaraldehyde in the presence of magnetite. The sorption characteristics of this composite towards U(VI) at different experimental conditions were carried out by means of batch and column methods where it showed sorption capacity reached $2.32 \mathrm{mmol} / \mathrm{g}$ [9].

The main target of this paper was to increase the concentration of active sites available for interaction with the metal ions. The target was approached through spreading the resin as a film over iron oxide particles and using a crosslinker with hydrophilic characters. The other target of this paper was to increase the chemical and mechanical stability of modified glycidyl methacrylate resins with amine moiety to enhance their adsorption capacities towards U(VI) ions from the aqueous solutions. The target was approached through increasing degree of cross-linking as well as modifying all parameters that affect the polymerization process such as the continuous phase, initiator, diluents, and polymerization temperature. In the present work, GMA/MBA was prepared by suspension polymerization of GMA with MBA in the presence of nanomagnetite particles. Different amine moieties were immobilized on the magnetic GMA/MBA copolymers. The obtained magnetic resins were applied for separation of $\mathrm{U}(\mathrm{VI})$ ions from aqueous solutions. The different factors affecting the separation process such as initial concentration of the metal ion, $\mathrm{pH}$, shaking time, and temperature were studied. Kinetic and thermodynamic parameters of the adsorption process were calculated.

\section{Materials and Methods}

All the chemicals were of analytical grade of Merck or SigmaAldrich trademark and were used as received without further purification. All of the solutions were prepared with fresh double distilled water. A uranium stock solution containing $1000 \mathrm{mg} \mathrm{L}^{-1}$ of $\mathrm{U}(\mathrm{VI})$ was prepared by dissolving $1.782 \mathrm{~g}$ of uranyl acetate in $1 \%$ nitric acid, and diluting to $1000 \mathrm{~mL}$ using the double distilled water.

The U(VI) measurement was estimated spectrophotometrically using Arsenazo I method [11] by the PC scanning spectrophotometer UV/VIS double beam of the type Labomed, Inc. (USA).

Nanomagnetite was prepared following the modified Massart method [10]. $100 \mathrm{~mL}(0.2 \mathrm{M})$ of $\mathrm{Fe}^{+3}$ solutions was added, with stirring, to freshly prepared $100 \mathrm{~mL}(0.1 \mathrm{M})$ of $\mathrm{Fe}^{+2}$ solutions. Then, $100 \mathrm{~mL}$ of ammonia solution (30\%) was suddenly poured to the previously prepared $\mathrm{Fe}^{+3} / \mathrm{Fe}^{+2}$ solutions with vigorous stirring. A black precipitate was formed and was allowed to crystallize for $30 \mathrm{~min}$ with stirring. The precipitate was washed with deoxygenated water (water was boiled to repeal any gases and then bubbled with nitrogen gas) under magnetic decantation until $\mathrm{pH}$ of suspension became below 7.5. The precipitate was dried at room temperature to give a black powder.

Magnetic GMA/MBA was prepared through suspension copolymerization of GMA in the presence of crosslinking agent (MBA), nanomagnetite $\left(\mathrm{F}_{3} \mathrm{O}_{4}\right)$, and 2,2azobis(isobutyronitrile) (AIBN) as an initiator following the previously reported method [10]. The contents were refluxed on a water bath at $80^{\circ} \mathrm{C}$ with continuous stirring for $8 \mathrm{~h}$. A heavy precipitate was formed, filtered off, washed with water and ethanol to remove the diluents, and then dried.

Two portions of the magnetic GMA/MBA copolymers were weighted, $2 \mathrm{~g}$ each. One of them was added portionwise to the stirred solution of $10 \mathrm{~mL}$ ethylenediamine (DA) while the second portion was added to diethylenetriamine (TA) in proper flasks. The mixtures were placed in an oil bath at $80^{\circ} \mathrm{C}$ for $72 \mathrm{~h}$, with stirring speed of $300 \mathrm{rpm}$. After completion of the reaction, the formed beads were simply decanted and washed several times and then dried. The obtained resins were marked as R-1 and R-2, respectively.

Adsorption experiments under controlled $\mathrm{pH}$ were carried out by adding portions of $0.05 \mathrm{~g}$ resin in a series of flasks, each one containing $100 \mathrm{~mL}$ solution of $\left(100 \mathrm{~m} \mathrm{~L}^{-1}\right)$ $\mathrm{U}(\mathrm{VI})$ ions solution. The $\mathrm{pH}$ was adapted in the range of 1-5 using nitric acid or sodium hydroxide solutions. The flasks were shaken on a shaking water bath model 1083 (Labortechnik GmbH, Germany) at $300 \mathrm{rpm}$ for $2 \mathrm{~h}$ at $25^{\circ} \mathrm{C}$. After equilibration, the residual concentration of the metal ion was determined.

To conduct the time effect, $0.05 \mathrm{~g}$ of R-1 or R-2 was put in a series of flasks containing $100 \mathrm{~mL}$ of $\mathrm{U}(\mathrm{VI})$ ions solution $\left(100 \mathrm{mg} \mathrm{L}^{-1}\right)$ at $\mathrm{pH}$ 5. The flasks were shaken on a shaking water bath for the required time period. The effect of initial concentration of U(VI) ion was carried out at definite concentrations $\left(20-120 \mathrm{mg} \mathrm{L}^{-1}\right)$ and $\mathrm{pH}$ 5. The contents of the flasks were equilibrated on a shaking water bath while keeping the temperature at $25,30,40$, and $50^{\circ} \mathrm{C}$. After adsorption, the residual $\mathrm{U}(\mathrm{VI})$ concentration of the metal ion was determined.

The effect of the solid/liquid ratio on the adsorption efficiency of the studied resins was achieved by varying the amount of beads from 0.025 to $0.125 \mathrm{~g}$ in the adsorption medium $\left(100 \mathrm{~mL}\right.$ containing $\left.100 \mathrm{mg} \mathrm{L}^{-1} \mathrm{U}(\mathrm{VI})\right)$, while keeping other parameters ( $\mathrm{pH}$, contact time, and temperature) constant according to their values obtained from the previous experiments.

\section{Results and Discussions}

Scheme 1 shows the preparation of the magnetic GMA/MBA resins and their chemical modification with DA or TA, through epoxide ring, to give R-1 and R-2, respectively, as shown in Scheme 1.

The structural characteristics of the resins obtained were verified using FT-IR measurements. The spectra of resins showed the stretching band of oxirane group of magnetic GMA/MBA at $910 \mathrm{~cm}^{-1}$ disappeared in the spectra of resins 
<smiles>C=CC(=O)NCNC(=O)C=C[In]1CC1COC(=O)C(=C)C</smiles><smiles>[R]CC([R])C(=O)NCNC(=O)C([R])C[C@@](C)(C[R9])C(=O)OCC1CO1</smiles>

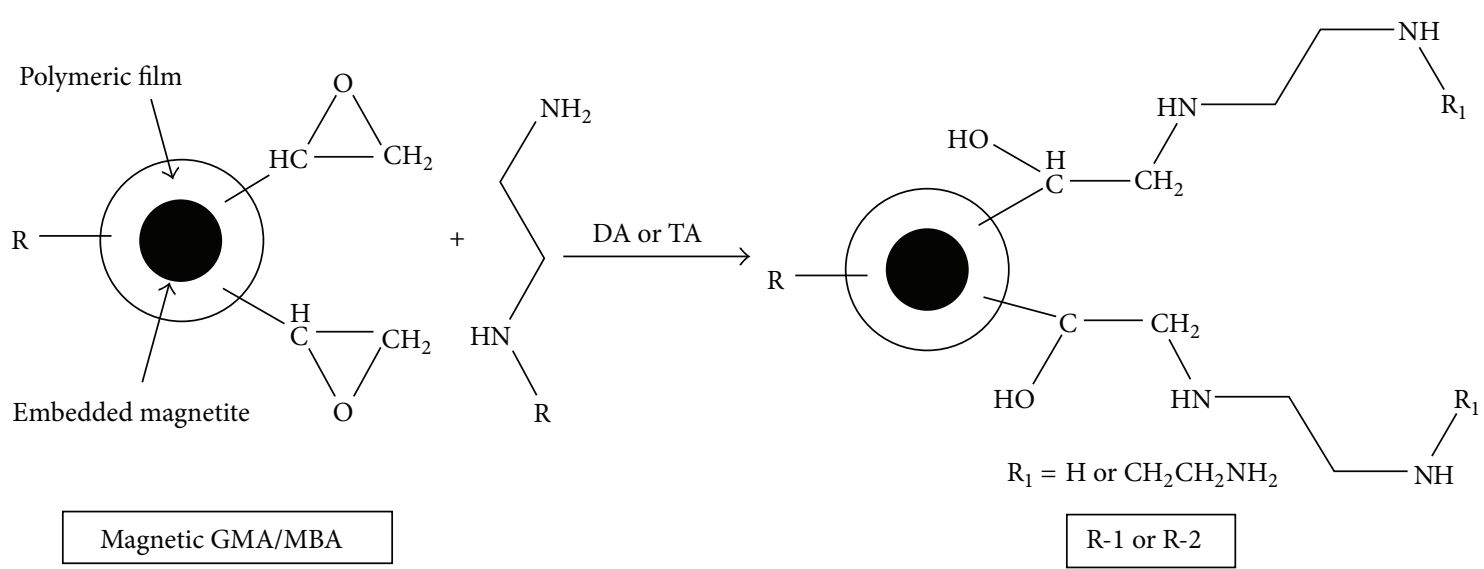

SCHEME 1: Chemical preparation of resins containing nanomagnetite.

R-1 and R-2. Moreover, the spectra of R-1 and R-2 are characterized by $v \mathrm{NH}_{2}$ at $3443 \mathrm{~cm}^{-1}$. This indicates the success of modification process. Energy dispersive X-ray measurements (EDX) of R-1 and R-2 showed that the resin contains a weight percentage of $10 \%$ of $\mathrm{Fe}_{3} \mathrm{O}_{4}$. The resin particles of magnetite, R-1, and R-2 were characterized by dynamic light scattering (DLS). The average sizes of magnetite particles were 18$92 \mathrm{~nm}$, while the average sizes of R-1 and R-2 particles were $615 \mathrm{~nm}-4801 \mathrm{~nm}$.

The chemical stability of R-1 and R-2 in acid and alkaline media was tested by shaking a $0.5 \mathrm{~g}$ portion of the resins in turn with $100 \mathrm{~mL}$ of $1 \mathrm{M} \mathrm{HCl}$ and $1 \mathrm{M} \mathrm{NaOH}$ for $24 \mathrm{~h}$. The resins were then filtered off and washed with water. The adsorption capacities after the treatments were reduced by only $5-7 \%$, which were denoted as desirable stability of the resin. No obvious leakage of resins and change of resins were observed in the experimental process.

3.1. Effect of $p H$. Sorption of $\mathrm{U}(\mathrm{VI})$ from aqueous solutions by R-1 and R-2 was determined under noncompetitive conditions at different $\mathrm{pH}$ values as shown in Figure 1. The

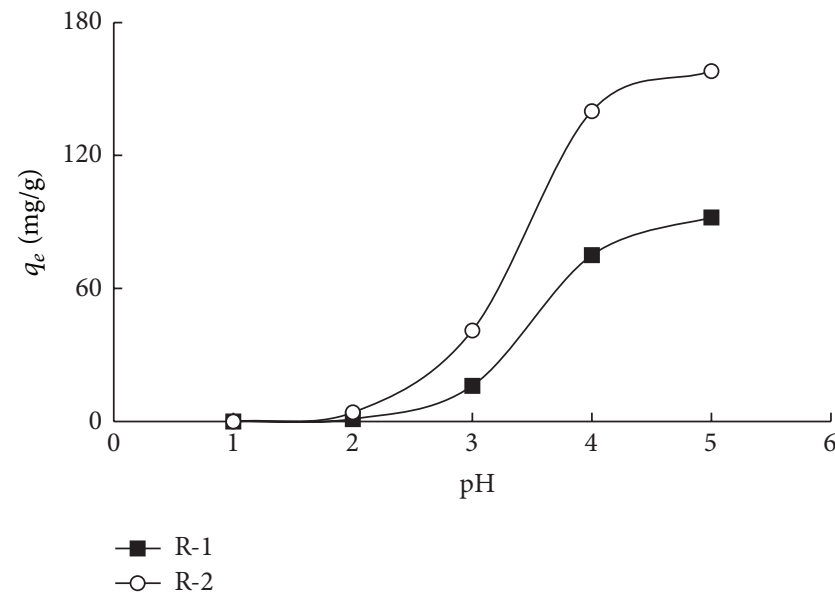

Figure 1: Effect of $\mathrm{pH}$ on adsorption process.

sorption of uranium was found to be increased as the solution $\mathrm{pH}$ increased. The maximum sorption capacities were observed at $\mathrm{pH} 5$ for R-1 and R-2. As indicated in Table 1, 

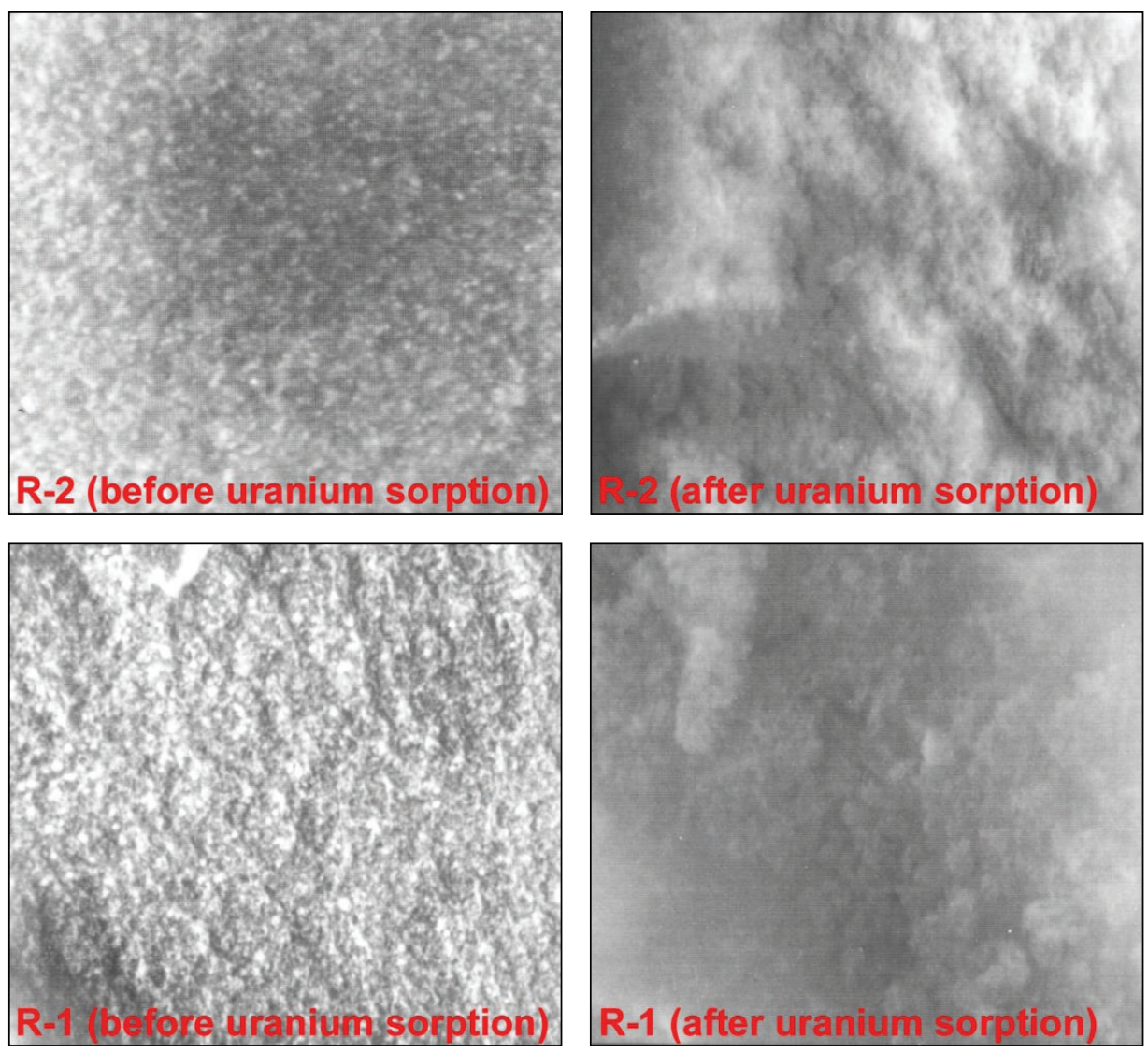

FIGURE 2: The scanning electron microscopy images of the studied resins before and after uranium sorption.

TABLE 1: Adsorption capacities of uranium by different adsorbents.

\begin{tabular}{lcc}
\hline Chelating resins & $q_{e}(\mathrm{mg} / \mathrm{g})$ & Reference \\
\hline Modified polystyrene & 59.5 & {$[18]$} \\
Calix[4]resorcinarene & 64.0 & {$[19]$} \\
Tetramethylmalonamide (TMMA) & 119.0 & {$[20]$} \\
Amberlite XAD-4-succinic acid & 12.3 & {$[21]$} \\
Modified Dowex ${ }^{\mathrm{Tw}}$ 12 K & 49.8 & {$[22]$} \\
Nanoporous silica & 29.4 & {$[23]$} \\
Mesoporous carbon CMK-5 & 65.2 & {$[24]$} \\
4-Vinylpyridine & 134 & {$[25]$} \\
Salicylaldoxime and 4-vinylpyridine & 1.2 & {$[26]$} \\
IRA-402 resin & 213 & {$[27]$} \\
Covalent organic frameworks & 81 & {$[28]$} \\
Salicylaldoxime and 4-vinylpyridine & 1.15 & {$[29]$} \\
R-1 & 92 & This work \\
R-2 & 158 & This work \\
\hline
\end{tabular}

the investigated resins were characterized by higher $q_{e}$ value relative to that reported by others.

The surface morphology of the studied resins before and after uranium sorption was studied by SEM analysis (Figure 2). The surface morphology of the uranium loaded resins showed a large particle with close-packed plane surface, which could be assigned to the sorption of uranium ions onto the surface of the studied loaded resins.

The observed lower sorption of U(VI) ions in higher acidic medium may be attributed to the partial protonation of the amino groups to give positively charged protonated amino groups that do not promote $\mathrm{U}(\mathrm{VI})$ adsorption due to repulsion force.

Hydrolysis of U(VI) ions was observed to begin at $\mathrm{pH}>5$ and various positively charged hydrolyzed uranium species exist $\left(\left[\left(\mathrm{UO}_{2}\right)_{3}(\mathrm{OH})_{4}\right]^{2+},\left[\left(\mathrm{UO}_{2}\right)_{2} \mathrm{OH}\right]^{3+},\left[\left(\mathrm{UO}_{2}\right)_{3}(\mathrm{OH})\right]^{5+}\right.$, and $\left.\left[\left(\mathrm{UO}_{2}\right)_{4}(\mathrm{OH})\right]^{7+}\right)$ which have lower affinity to R-1 and R2. Also, negatively charged uranium species $\left(\left[\mathrm{UO}_{2}(\mathrm{OH})_{4}\right]^{2-}\right.$ and $\left.\left[\left(\mathrm{UO}_{2}\right)_{3}(\mathrm{OH})_{7}\right]^{-}\right)$were found at higher $\mathrm{pH}$ values which cannot react with R-1 and R-2 [10-12].

The values of the experimental maximum sorption capacities were 92 and $158 \mathrm{mg} / \mathrm{g}$ for R-1 and R-2. The values of the maximum sorption of resins are related to their amine group content of 5.5 and $8.1 \mathrm{mmol} / \mathrm{g}$ for R-1 and R-2. The higher concentration of amine active sites in case of R-1 and R-2 relative to the free magnetite ones ( 3.8 and $5.4 \mathrm{mmol} / \mathrm{g}$ ) may indicate the formation of extended thin film of the resin over the metal oxide particles. This would allow the active sites hidden within the core of the resin matrix to become more exposed for interaction with metal ions [10].

The mechanism of interaction between $\mathrm{U}(\mathrm{VI})$ ions and amine active sites on R-1 and R-2 resins may be related to their coordination modes. U(VI) ions can coordinate by 


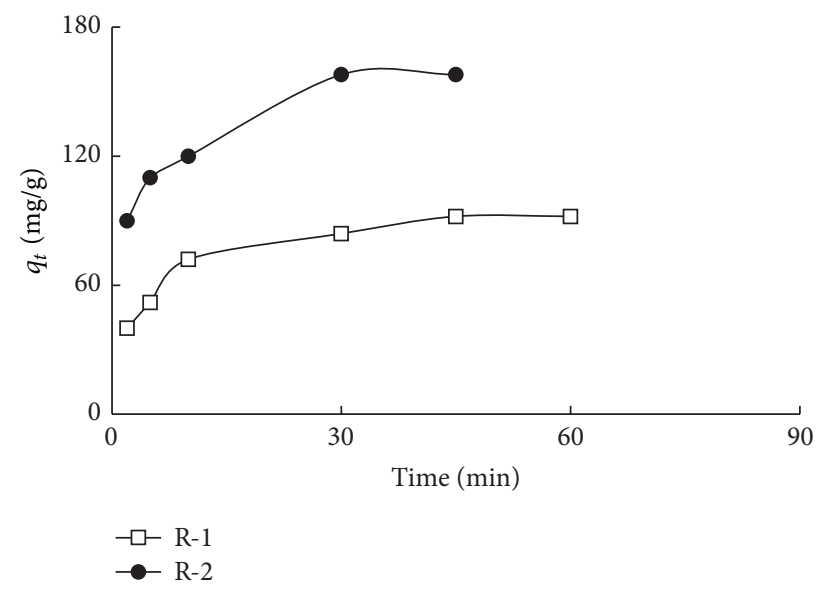

Figure 3: Effect of time on adsorption process.

four, five, or six amine active sites of R-1 and R-2 resins [10]. The molar ratios of sorbed $\mathrm{U}(\mathrm{VI})$ ions and resins active sites are $1: 4,1: 5$, and $1: 6$. The experimental maximum sorption capacities of $92 \mathrm{mg} / \mathrm{g}(0.39 \mathrm{mmol} / \mathrm{g})$ and $158 \mathrm{mg} / \mathrm{g}$ $(0.66 \mathrm{mmol} / \mathrm{g})$ for R-1 and R-2 are closer to the theoretical sorption value corresponding to the molar ratio of $1: 6(0.92$ and $1.4 \mathrm{mmol} / \mathrm{g}$ for R-1 and R-2). The observed differences between the experimental and expected sorption capacities values may be attributed to the nonaccessibility of all active sites for coordination with U(VI). This behavior confirms the effect of textural properties on the nature of binding as well as the sorption capacity.

3.2. Effect of Contact Time and Adsorption Kinetics. Sorption of $\mathrm{U}(\mathrm{VI})$ on both $\mathrm{R}-1$ and $\mathrm{R}-2$ resins was investigated as a function of contact time and the data obtained are shown in Figure 3. Uranium sorption increased as the contact time increased and reached its maximum sorption capacities at 45 and 30 min on R-1 and R-2, respectively. To verify the order of the adsorption process pseudo-first-order kinetics and pseudo-second-order kinetics models $[10,12]$ were tested according to the following equations:

$$
\begin{gathered}
\text { Pseudo first order } \log \left(q_{e}-q_{t}\right)=\log \left(q_{1 \mathrm{st}}\right)-\frac{k_{1}}{2.303} t \\
\text { Pseudo second order } \frac{t}{q_{t}}=\frac{1}{k_{2} q_{2 \mathrm{nd}}^{2}}+\frac{1}{q_{e}} t
\end{gathered}
$$

where $q_{e}$ is the maximum experimental sorption capacity $\left(\mathrm{mg} \mathrm{g}^{-1}\right), q_{t}$ is the experimental sorption capacity at time $(t)$ $\left(\mathrm{mg} \mathrm{g}^{-1}\right), q_{1 \text { st }}$ is the calculated sorption capacity according to pseudo-first-order model $\left(\mathrm{mg} \mathrm{g}^{-1}\right), k_{1}$ is the rate constant of pseudo-first-order $\left(\mathrm{min}^{-1}\right), q_{2 \mathrm{nd}}$ is the calculated sorption capacity according to pseudo-second-order model $\left(\mathrm{mg} \mathrm{g}^{-1}\right)$, and $k_{2}$ is the rate constant of pseudo-second-order $\left(\mathrm{min}^{-1}\right)$. Values of $k_{1}$ and $q_{1 \text { st }}$ were calculated from the slope and intercept values of plotting $\log \left(q_{e}-q_{t}\right)$ versus $(t)$ as shown in Figure 4 . The plot of $t / q_{t}$ versus $(t)$ (Figure 5) gives a straight line with slope and intercept equal to $1 / q_{e}$ and $1 / k_{2} q_{e}{ }^{2}$,

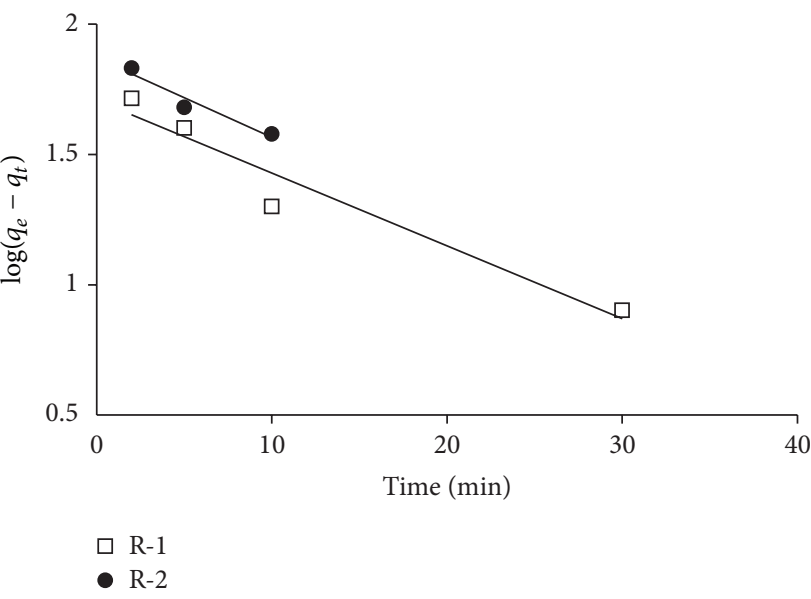

FIgURE 4: The pseudo-first-order kinetics model.

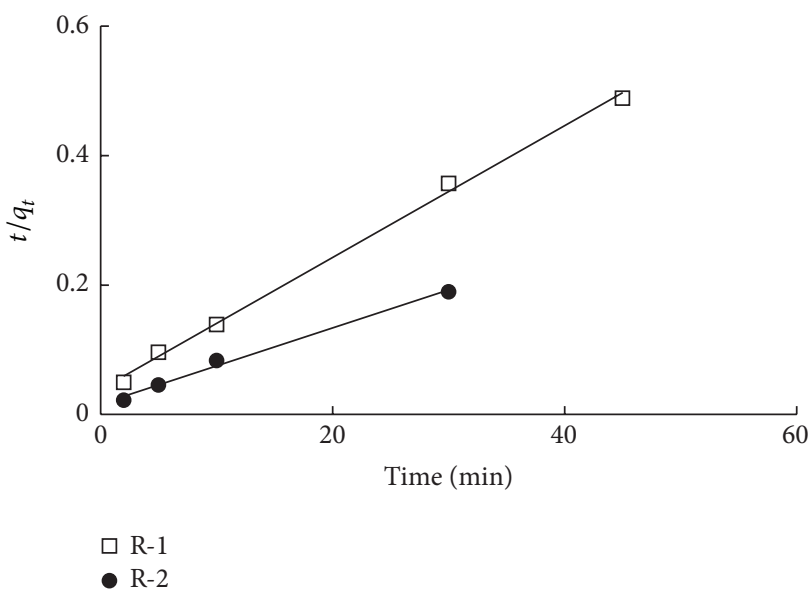

Figure 5: The pseudo-second-order kinetics model.

respectively. The calculated values of $k_{1}, q_{1 \text { st }}, k_{2}$, and $q_{2 \text { nd }}$ were reported in Table 2.

The obtained data $\left(q\right.$ and $R^{2}$ ) proved that the adsorption rate is likely to be controlled by pseudo-second-order kinetic model rather than the pseudo-first-order kinetic model. The rate of adsorption is less controlled by intraparticle diffusion due to the bulky size of U(VI) ions that implies that adsorption of $\mathrm{U}(\mathrm{VI})$ is dependent on concentration of both the metal ions and active sites concentrations.

3.3. Effect of Adsorption Temperature. The temperature effect on U(VI) adsorption was tested as function of 4 temperature degrees (298, 303, 313, and 323) (Figure 6). An increase in temperature resulting in an increase in the amount of $\mathrm{U}(\mathrm{VI})$ adsorbed per unit mass of all resins might be attributed to the change in surface properties of the sorbent and solubility of the solute species with endothermic nature of the sorption process.

3.4. Adsorption Isotherms. A relation between the amount of adsorbate adsorbed on a given surface at constant temperature and the equilibrium concentration of the substrate in 
TABLE 2: Kinetic data for adsorption of U(VI) on R-1 and R-2 resins.

\begin{tabular}{lcccccr}
\hline \multirow{2}{*}{ Resin } & Experimental & \multicolumn{3}{c}{ Pseudo-first-order kinetics } & \multicolumn{3}{c}{ Pseudo-second-order kinetics } \\
& $q_{e}(\mathrm{mg} / \mathrm{g})$ & $q_{1 \mathrm{st}}(\mathrm{mg} / \mathrm{g})$ & $k_{1}\left(\mathrm{~min}^{-1}\right)$ & $R^{2}$ & $q_{2 \mathrm{nd}}(\mathrm{mg} / \mathrm{g})$ & $k_{2}\left(\mathrm{~min}^{-1}\right)$ \\
\hline $\mathrm{R}-1$ & 92 & 51.17 & 0.06 & 0.942 & 100 & 0.003 \\
$\mathrm{R}-2$ & 158 & 74.13 & 0.07 & 0.935 & 200 & 0.997 \\
\hline
\end{tabular}
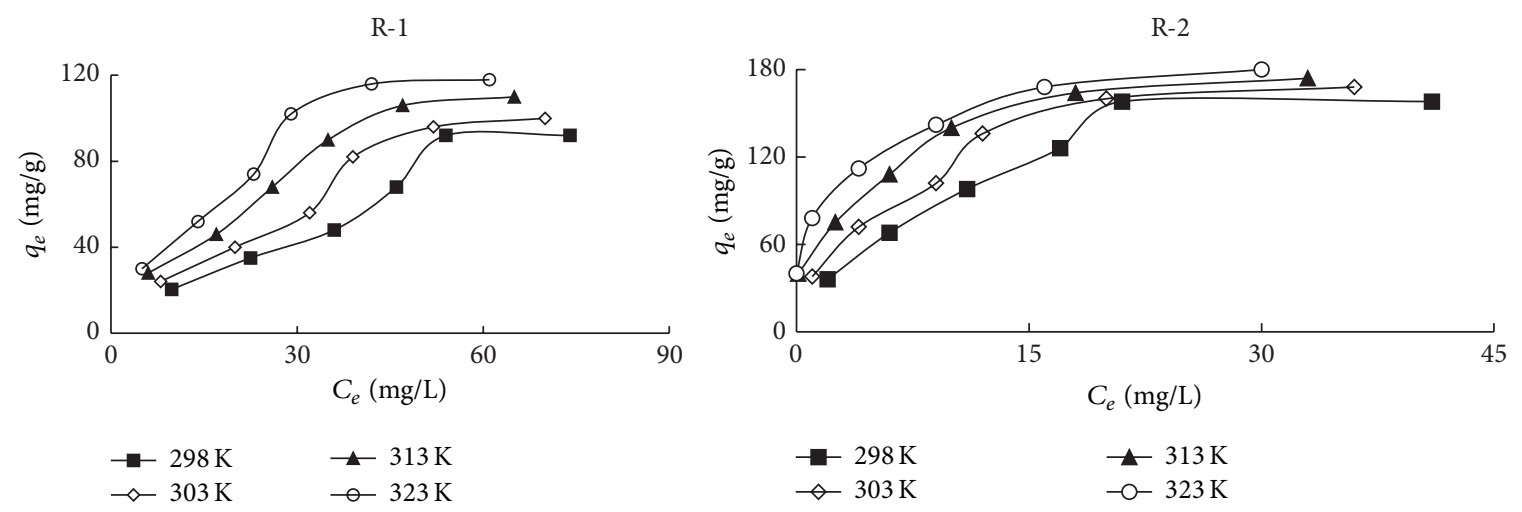

FIGURE 6: Effect of adsorption temperature on adsorption process.
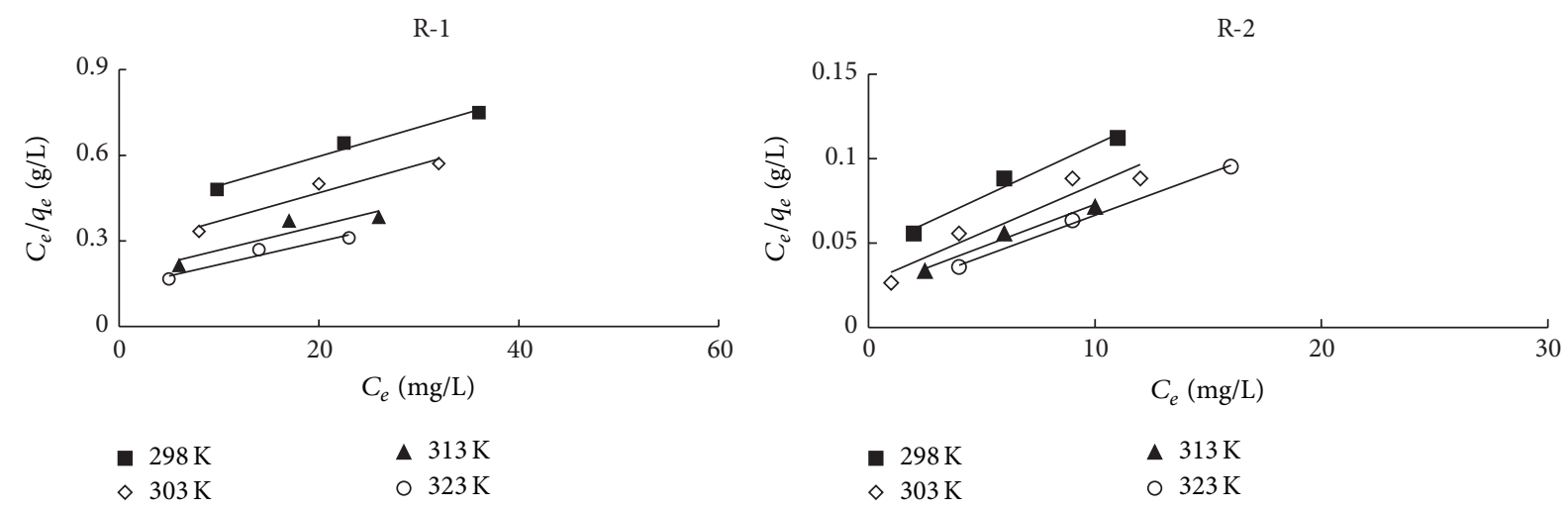

FIGURE 7: Langmuir adsorption isotherm.

contact with the adsorbent is known as adsorption isotherm. Adsorption isotherms depend on certain parameters, whose values express the surface properties and the affinity of the sorbent. We can compute experimental results from equilibrium experiences by several adsorption isotherm models.

(1) Langmuir Model. The most widely used isotherm equation for modeling equilibrium data is the Langmuir model. Langmuir derived a relation between adsorbed material and its equilibrium concentration $[10,13,14]$. The linear form of Langmuir equation is given by

$$
\frac{C_{e}}{q_{e}}=\frac{C_{e}}{q_{\max }}+\frac{1}{K_{L} Q_{\max }},
$$

where $C_{e}$ is the equilibrium concentration of ions in solution $\left(\mathrm{mg} \mathrm{L}^{-1}\right), q_{e}$ is the amount adsorbed at $C_{e}\left(\mathrm{mgg}^{-1}\right), Q_{\max }$ is the maximum adsorption capacity $\left(\mathrm{mgg}^{-1}\right)$, and $K_{L}$ is the binding constant which is related to the energy of adsorption $\left(\mathrm{L} \mathrm{mg}^{-1}\right)$. Plotting $C_{e} / q_{e}$ against $C_{e}$ (Figure 7) gives a straight line with slope and intercept equal to $1 / Q_{\max }$ and $1 / K_{L} Q_{\max }$, respectively. The values of $K_{L}$ and $Q_{\max }$ at different temperatures are reported in Table 3 . The values of $K_{L}$ and $Q_{\max }$ increase as the temperature increases. Increasing of $K_{L}$ value with increasing of temperature implies the strong binding between $\mathrm{U}(\mathrm{VI})$ ions and the active sites at elevated temperatures.

The thermodynamic parameters such as enthalpy change $\left(\Delta H^{\circ}\right)$ and entropy change $\left(\Delta S^{\circ}\right)$ corresponding to U(IV) sorption on the studied resins were calculated using Van't Hoff equation [10]

$$
\ln K_{L}=\frac{\Delta S^{\circ}}{R}-\frac{\Delta H^{\circ}}{R T},
$$

where $R$ is the universal gas constant $\left(8.314 \mathrm{~J} \mathrm{~mol}^{-1} \cdot \mathrm{K}^{-1}\right)$ and $T$ is the absolute temperature (Kelvin). Plotting $\ln K_{L}$ against $1 / T$ (Figure 8 ) gives a straight line with intercept and slope equal to $\Delta S^{\circ} / R$ and $-\Delta H^{\circ} / R$, respectively. The values of $\Delta S^{\circ}$ and $\Delta H^{\circ}$ were calculated and reported in 
TABLE 3: Isotherms parameters for the sorption of $U(V I)$ ions.

\begin{tabular}{|c|c|c|c|c|c|c|c|}
\hline \multirow{2}{*}{ Resin } & \multirow{2}{*}{ Experimental $q_{e}(\mathrm{mg} / \mathrm{g})$} & \multicolumn{3}{|c|}{ Langmuir parameters } & \multicolumn{3}{|c|}{ Freundlich parameters } \\
\hline & & $K_{L}(\mathrm{~L} / \mathrm{mol})$ & $Q_{\mathrm{Max}}(\mathrm{mg} / \mathrm{g})$ & $R^{2}$ & $n$ & $K_{f}(\mathrm{mg} / \mathrm{g})$ & $R^{2}$ \\
\hline $\mathrm{R}-1$ & 92 & 0.026 & 100 & 0.981 & 1.247 & 3.083 & 0.9907 \\
\hline $\mathrm{R}-2$ & 158 & 0.133 & 166.67 & 0.977 & 1.887 & 26.485 & 0.8233 \\
\hline \multirow{2}{*}{ Resin } & \multicolumn{3}{|c|}{ Temkin parameters } & \multicolumn{4}{|c|}{ D-R parameters } \\
\hline & $B(\mathrm{~J} / \mathrm{mol})$ & $A_{T}(\mathrm{~L} / \mathrm{g})$ & $R^{2}$ & $q_{s}(\mathrm{mg} / \mathrm{g})$ & $K_{\mathrm{ad}}\left(\mathrm{mol}^{2} / \mathrm{kJ}^{2}\right)$ & $E\left(\mathrm{~kJ} / \mathrm{mol}^{2}\right)$ & $R^{2}$ \\
\hline $\mathrm{R}-1$ & 54.14 & 0.080 & 0.871 & 94.54 & $9 \times 10^{-5}$ & 74.54 & 0.85 \\
\hline $\mathrm{R}-2$ & 51.27 & 0.681 & 0.934 & 169.7 & $5 \times 10^{-5}$ & 100 & 0.923 \\
\hline
\end{tabular}

TABLE 4: Thermodynamic parameters for adsorption of U(VI) by R-1 and R-2 at different temperatures.

\begin{tabular}{|c|c|c|c|c|c|}
\hline \multirow{2}{*}{ Resin } & \multirow{2}{*}{ Temp. (Kelvin) } & \multicolumn{4}{|c|}{ Thermodynamic parameters } \\
\hline & & $\Delta H^{\circ}(\mathrm{kJ} / \mathrm{mol})$ & $\Delta S^{\circ}(\mathrm{KJ} / \mathrm{mol} \cdot \mathrm{K})$ & $T \Delta S^{\circ}(\mathrm{kJ} / \mathrm{mol})$ & $\Delta G^{\circ}(\mathrm{kJ} / \mathrm{mol})$ \\
\hline \multirow{4}{*}{$\mathrm{R}-1$} & 298 & \multirow{4}{*}{27.328} & \multirow{4}{*}{0.16445} & 49.01 & -21.68 \\
\hline & 303 & & & 49.83 & -22.5 \\
\hline & 313 & & & 51.47 & -24.14 \\
\hline & 323 & & & 53.12 & -25.79 \\
\hline \multirow{4}{*}{$\mathrm{R}-2$} & 298 & \multirow{4}{*}{26.064} & \multirow{4}{*}{0.1741} & 51.88 & -25.82 \\
\hline & 303 & & & 52.75 & -26.69 \\
\hline & 313 & & & 54.49 & -28.43 \\
\hline & 323 & & & 56.23 & -30.17 \\
\hline
\end{tabular}

Table 4 . The positive $\Delta H^{\circ}$ value indicates that the adsorption process is endothermic. The positive value of $\Delta S^{\circ}$ may be explained by the increased degree of randomness at the resin/solution interface during the progress of sorption process. This phenomenon could be ascribed to liberation of free water molecules as a result of the substitution reaction between chelating amine active sites and hydrated U(VI) ion. The Gibbs free energy of adsorption reaction $\left(\Delta G^{\circ}\right)$ was calculated using the following relation [10]:

$$
\Delta G^{\circ}=\Delta H^{\circ}-T \Delta S^{\circ} .
$$

The values of $\Delta G^{\circ}$ values (Table 4) confirm the spontaneous nature and feasibility of the sorption process and the favorable $\mathrm{U}(\mathrm{VI})$ sorption takes place with increasing of temperature.

The suitability of the resins towards metal ions is through the values of separation factor constant $\left(R_{L}\right)$, where $R_{L}>1$ (unsuitable); $R_{L}=1$ (linear); $0<R_{L}<1$ (suitable); $R_{L}=0$ (irreversible) [10]. The value of $R_{L}$ could be calculated from (4):

$$
R_{L}=\frac{1}{1+K_{L} C_{o}}
$$

where $C_{o}$ is the initial concentration of $\mathrm{U}(\mathrm{VI})$ ions $(\mathrm{mM})$. The values of $R_{L}$ for sorption of $\mathrm{U}(\mathrm{VI})$ on $\mathrm{R}-1$ and $\mathrm{R}-2$ resins at different temperature were calculated and found to lie between 0.041 and 0.281 indicating their suitability as adsorbents for $\mathrm{U}(\mathrm{VI})$.

(2) Freundlich Model. The Freundlich isotherm model [15, 16] is an empirical relationship that describes the sorption of solutes on a solid surface assuming that different sites

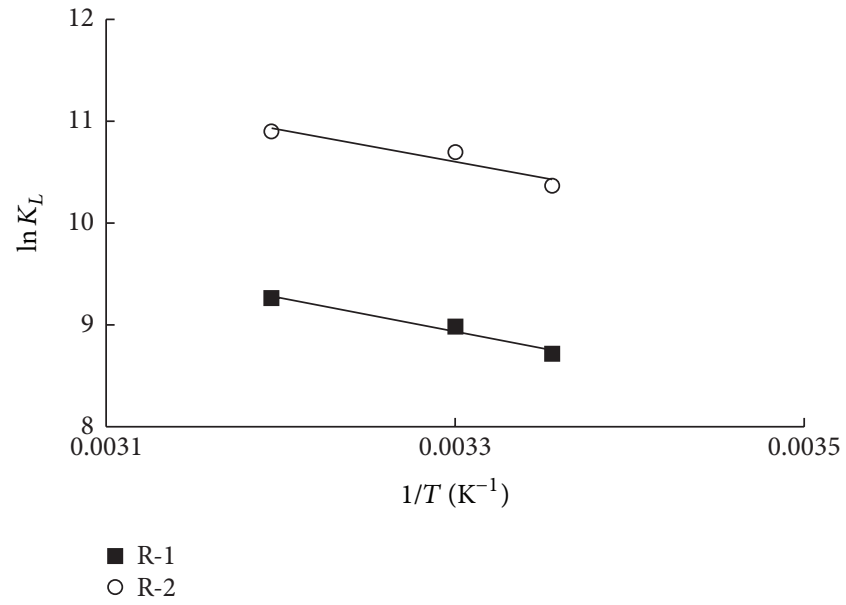

FIGURE 8: Van't Hoff plots for the adsorption process.

with several sorption energies are involved (the surface of adsorbent is heterogeneous). This isotherm model is given by (3):

$$
\log q_{e}=\log K_{F}+\frac{\log C_{e}}{n}
$$

where $q_{e}\left(\mathrm{mgg}^{-1}\right)$ and $C_{e}\left(\mathrm{mg} \mathrm{L}^{-1}\right)$ are the equilibrium concentrations of $\mathrm{U}(\mathrm{VI})$ in the solid and liquid phase, respectively. $K_{F}\left(\mathrm{mg} \mathrm{g}^{-1}\right)$ and $\mathrm{n}$ are characteristic constants related to the relative sorption capacity of the sorbent and the intensity of sorption, respectively. The higher the $1 / n$ value is, the more favorable the adsorption is; generally, $n<1.1 / n$ and $\log K_{F}$ are the slope and intercept, respectively, given by 


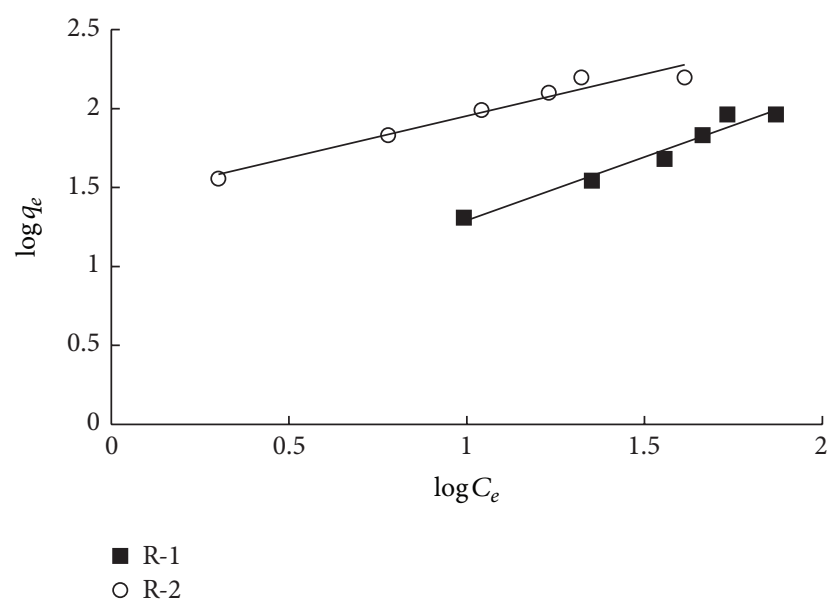

FIGURE 9: Freundlich adsorption isotherms.

plotting $\log q_{e}$ against $\log C_{e}$. The Freundlich plot (Figure 9) gave a slope less than unity indicating the nonlinear sorption behavior with $\mathrm{U}(\mathrm{VI})$ in the concentration range studied. The observed values of $K_{F}$ of R-1 and R-2 were found to be 3.05 and $26.49\left(\mathrm{mg} \mathrm{g}^{-1}\right)$. The values of equilibrium sorption capacity and correlation coefficients of Langmuir equation $\left(Q_{\max }\right)$ are more consistent with the experimental data than Freundlich isotherm model. Therefore, the sorption reaction is more favorable by Langmuir model, confirming the monolayer coverage of uranium onto the amine resins.

(3) Temkin's Model. The derivation of the Temkin isotherm assumes that the fall in the heat of sorption is linear rather than logarithmic, as implied in the Freundlich equation [15, 16]. The linear form of Temkin isotherm is given by the following equation:

$$
\begin{aligned}
q_{e} & =\frac{R T}{b} \ln A_{T}+\frac{R T}{b} \ln C_{e}, \\
B & =\frac{R T}{b}, \\
q_{e} & =B \ln A_{T}+B \ln C_{e},
\end{aligned}
$$

where $A_{T}$ is Temkin isotherm equilibrium binding constant $(\mathrm{L} / \mathrm{g}), b$ is Temkin isotherm constant, $R$ is universal gas constant $(8.314 \mathrm{~J} / \mathrm{mol} / \mathrm{K}), T$ is temperature at $298 \mathrm{~K}$, and $B$ is constant related to heat of sorption $(\mathrm{J} / \mathrm{mol})$, where $q_{e}$ $\left(\mathrm{mg} \mathrm{g}^{-1}\right)$ and $C_{e}\left(\mathrm{mg} \mathrm{L}^{-1}\right)$ are the equilibrium concentrations of U(VI) in the solid and liquid phase, respectively. Plotting $q_{e}$ versus $\ln C_{e}$ (Figure 10) should give a straight line if the adsorption energy decreases linearly with increasing surface coverage. According to the given relation of $q_{e}$ versus $\ln C_{e}$, the estimated $B$ values of R-1 and R-2 were $51.27-54.14 \mathrm{~J} / \mathrm{mol}$ that indicate the favorability of the chemical adsorption process.

3.4.1. Dubinin-Radushkevich Isotherm Model. The DubininRadushkevich (D-R) isotherm model is more general than the Langmuir isotherm as its deviation is not based on ideal

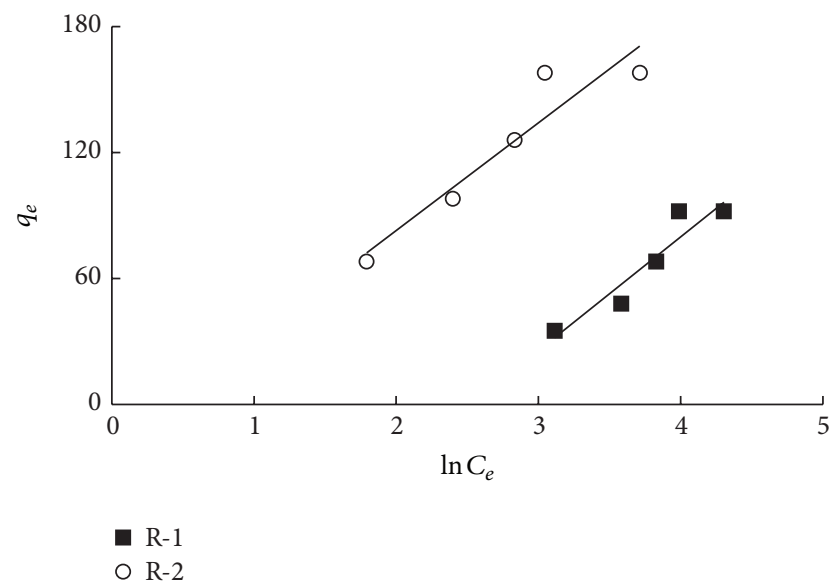

FIGURE 10: Temkin adsorption isotherms.

assumptions such as equipotential of sorption sites, absence of steric hindrances between sorbed and incoming particles, and surface homogeneity on microscopic level. This isotherm model is a temperature-dependent model used to estimate the characteristic porosity in addition to the apparent energy of adsorption as well as expressing the adsorption mechanism $[15,17]$. The model is represented by the following equations:

$$
\begin{aligned}
q_{e} & =\left(q_{s}\right) \exp \left(-K_{\mathrm{ad}}\left(R T \ln \left[1+\frac{1}{C_{e}}\right]\right)^{2}\right), \\
\varepsilon & =R T \ln \left[1+\frac{1}{C_{e}}\right], \\
q_{e} & =\left(q_{s}\right) \exp \left(-K_{\mathrm{ad}} \varepsilon^{2}\right),
\end{aligned}
$$

where $q_{e}$ is the amount of adsorbate in the adsorbent at equilibrium (mg/g), $q_{s}$ is the theoretical isotherm saturation capacity $(\mathrm{mg} / \mathrm{g}), K_{\mathrm{ad}}$ is the D-R isotherm constant $\left(\mathrm{mol}^{2} / \mathrm{kJ}{ }^{2}\right)$ related to free energy of sorption, $\varepsilon$ is the $\mathrm{D}-\mathrm{R}$ isotherm constant, $R$ represents the gas constant $(8.314 \mathrm{~J} / \mathrm{mol} \mathrm{K}), T$ is absolute temperature $(\mathrm{K})$, and $C_{e}$ is adsorbate equilibrium concentration $(\mathrm{mg} / \mathrm{L})$. The linearity of D-R isotherm model is represented by the following equation:

$$
\ln q_{e}=\ln q_{s}-K_{\mathrm{ad}} \varepsilon^{2} .
$$

A plot of $\ln q_{e}$ versus $\varepsilon^{2}$ yielded straight lines indicating a good fit of the isotherm to the experimental data (Figure 11) and the values of $q_{s}$ and $K_{\text {ad }}$ for D-R isotherm were calculated (Table 3$). q_{s}$ and $R^{2}$ values were observed that this isotherm also gave very good description of the sorption process. The high values of $q_{s}$ show high sorption capacity. The approach was usually applied to distinguish the physical and chemical adsorption of metal ions with its mean free energy per molecule of adsorbate. The apparent energy $\left(E=\mathrm{KJ} / \mathrm{mol}^{2}\right)$ of adsorption can be computed calculated using the following relation:

$$
E=\left[\frac{1}{\sqrt{2 K_{\mathrm{ad}}}}\right]
$$




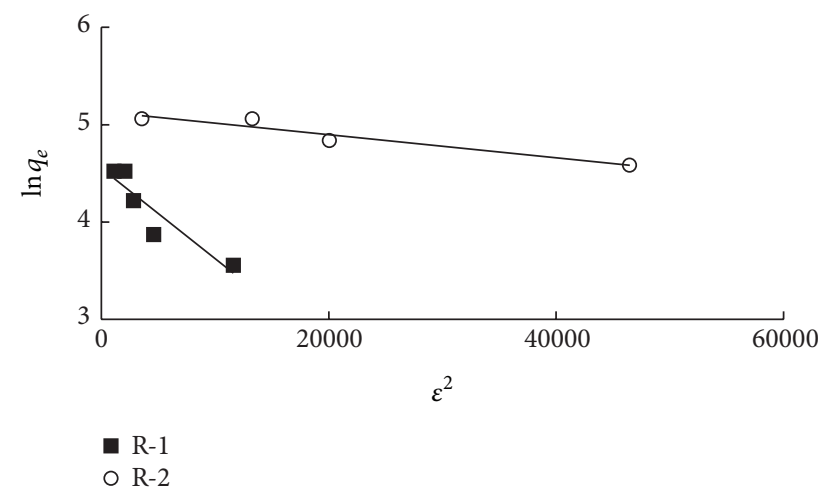

FIGURE 11: Dubinin-Radushkevich isotherm model.

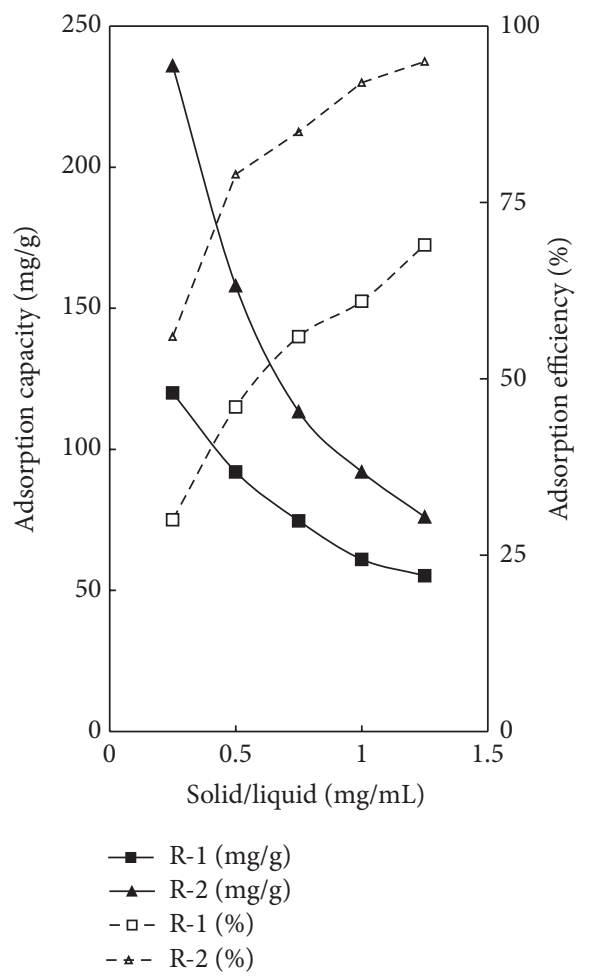

FIGURE 12: The effect of the solid/liquid ratio on the adsorption efficiency.

The values of the apparent energy of adsorption also depict chemisorption process.

3.5. Solid/Liquid Ratio. The effect of the solid/liquid ratio on the adsorption efficiency of the studied resins was achieved using variable amounts of R- 1 and $\mathrm{R}-2$ resins $(0.025$ to $0.125 \mathrm{~g}$ ) in $100 \mathrm{~mL}$ of the adsorption medium and the results were showed in Figure 12. The adsorption efficiency of the resins increased with increasing their dose while the adsorption capacities decreased. This result is reasonable if we consider that as the higher resin dose in the solution as the higher availability of active sites for metal ion adsorption.
3.6. Resin Regeneration. For desorption studies, $0.5 \mathrm{~g}$ of the uranium loaded dry resin with uranium was gently washed with distilled water to remove any unabsorbed metal ions and then shaken with $100 \mathrm{~mL}$ of $0.1 \mathrm{M} \mathrm{HNO}_{3}$ for $30 \mathrm{~min}$ and finally the uranium concentration was determined in the filtrate. All the experiments were performed in duplicate with experimental error $\pm 0.5-2 \%$. After the uranium elution, the resins were regenerated by washing with $1 \mathrm{M} \mathrm{NaOH}$ solution followed by washing with distilled water; hence the resin became regenerated and ready for the next use. Regeneration efficiency was found to be about $90-96 \%$ for two resins over 3 cycles.

It is worth mentioning that using of the eluted resins, without alkaline washing, failed to adsorb more uranium ions which can be ascribed to the protonation of the amino active groups that prevent the U(VI) ions adsorption. Accordingly, treatment with the alkaline solution converted these protonated groups into free ones which have the affinity towards the U(VI) ions.

3.7. Application of the Studied Resins for Granite Samples. Three granite rock samples were collected from Gabal Gattar pluton, located in North Eastern Desert of Egypt. The samples were crushed and ground to -200 mesh size and analyzed by conventional wet chemical techniques for their major oxide compositions as well as by XRF for some trace elements. The chemical analysis of the studied granitic samples is given in Table 5. The granitic samples contain high concentration of $\mathrm{Fe}_{2} \mathrm{O}_{3}(\mathrm{t}), \mathrm{Rb}, \mathrm{Y}, \mathrm{Nb}, \mathrm{U}$, and $\mathrm{Th}$ and low concentration of $\mathrm{Sr}$ and $\mathrm{Ba}$ compared with similar Egyptian granites.

For the work purpose, the uranium content in the granitic samples was selectively leached using nitric acid solution $(2 \mathrm{M})$ for 6 hours at $60^{\circ} \mathrm{C}$. The reacted slurry was filtered and washed with hot water. The obtained filtrate was treated with R-1 and R-2 for the uranium separation. The uptake results of $\mathrm{U}(\mathrm{VI})$ ions (Table 6) showed that both the resins displayed higher removal efficiency towards $\mathrm{U}(\mathrm{VI})$ relative to other metal ions present in sample solution.

\section{Conclusion}

Magnetic glycidyl methacrylate resin particles with nanomagnetite core and glycidyl methacrylate $/ \mathrm{N}, \mathrm{N}^{\prime}$-methylenebis-acrylamide resin shell were prepared and modified with DA and TA. The studied resins showed high adsorption capacities towards uranium ions reached 92 and $158 \mathrm{mg} / \mathrm{g}$ for R-1 and R-2, respectively. The results revealed that the pseudo-second-order sorption is the predominant mechanism. The amount of $\mathrm{U}(\mathrm{VI})$ adsorbed per unit mass of all resins increased as temperature increased showing the endothermic nature of the sorption process. The experimental results from equilibrium experiences were computed by several adsorption isotherm models Langmuir, Freundlich, Temkin, and Dubinin-Radushkevich isotherm model. The results showed that the sorption reaction is more favorable by Langmuir model confirming the monolayer coverage of uranium onto the amine resins and indicate the favorability of the chemical adsorption process. The positive heat of adsorption indicates that the adsorption process is endothermic. The 
TABLE 5: Chemical analysis of granitic samples.

\begin{tabular}{|c|c|c|c|c|}
\hline Sample & $\begin{array}{c}\text { Major } \\
\text { constituent }\end{array}$ & $\%$ & $\begin{array}{c}\text { Trace } \\
\text { constituent }\end{array}$ & $\begin{array}{c}\text { Concentration, } \\
\text { ppm }\end{array}$ \\
\hline \multirow{7}{*}{1} & $\mathrm{SiO}_{2}$ & 73.5 & $\mathrm{U}$ & 4000 \\
\hline & $\mathrm{AL}_{2} \mathrm{O}_{3}$ & 12.8 & Th & 300 \\
\hline & $\mathrm{Fe}_{2} \mathrm{O}_{3}$ & 2.5 & Rare earth & 270 \\
\hline & $\mathrm{CaO}$ & 1.3 & $\mathrm{Rb}$ & 225 \\
\hline & $\mathrm{Na}_{2} \mathrm{O}$ & 2.6 & $\mathrm{Zr}$ & 197 \\
\hline & $\mathrm{MgO}$ & 0.5 & $\mathrm{Y}$ & 126 \\
\hline & $\mathrm{K}_{2} \mathrm{O}$ & 2.4 & & \\
\hline \multirow{7}{*}{2} & $\mathrm{SiO}_{2}$ & 73.5 & $\mathrm{U}$ & 3200 \\
\hline & $\mathrm{AL}_{2} \mathrm{O}_{3}$ & 13.8 & $\mathrm{Th}$ & 190 \\
\hline & $\mathrm{Fe}_{2} \mathrm{O}_{3}$ & 3.6 & Rare earth & 270 \\
\hline & $\mathrm{CaO}$ & 1.4 & $\mathrm{Rb}$ & - \\
\hline & $\mathrm{Na}_{2} \mathrm{O}$ & 0.6 & $\mathrm{Zr}$ & 400 \\
\hline & $\mathrm{MgO}$ & 0.5 & $\mathrm{Y}$ & 197 \\
\hline & $\mathrm{K}_{2} \mathrm{O}$ & 2.4 & & \\
\hline \multirow{7}{*}{3} & $\mathrm{SiO}_{2}$ & 72.5 & $\mathrm{U}$ & 2700 \\
\hline & $\mathrm{AL}_{2} \mathrm{O}_{3}$ & 12.8 & Th & 260 \\
\hline & $\mathrm{Fe}_{2} \mathrm{O}_{3}$ & 2.5 & Rare earth & 250 \\
\hline & $\mathrm{CaO}$ & 1.3 & $\mathrm{Rb}$ & 437 \\
\hline & $\mathrm{Na}_{2} \mathrm{O}$ & 3.9 & $\mathrm{Zr}$ & 284 \\
\hline & $\mathrm{MgO}$ & 0.5 & $\mathrm{Y}$ & 135 \\
\hline & $\mathrm{K}_{2} \mathrm{O}$ & 3.4 & & \\
\hline
\end{tabular}

TABLE 6: Results of treatment of the granite samples with the studied resins.

\begin{tabular}{lcccc}
\hline \multirow{2}{*}{ Resin } & \multirow{2}{*}{ Metal ion } & \multicolumn{3}{c}{ Removal efficiency (\%) } \\
& & Sample 1 & Sample 2 & Sample 3 \\
\hline \multirow{2}{*}{ R-1 } & $\mathrm{U}(\mathrm{VI})$ & 93 & 93 & 92.8 \\
& $\mathrm{Fe}(\mathrm{III})$ & 26 & 25 & 26 \\
& $\mathrm{RE}_{2} \mathrm{O}_{3}$ & 15 & 15 & 15 \\
\hline \multirow{3}{*}{ R-2 } & $\mathrm{U}(\mathrm{VI})$ & 99.5 & 99.2 & 99 \\
& $\mathrm{Fe}(\mathrm{III})$ & 31 & 31 & 31 \\
& $\mathrm{RE}_{2} \mathrm{O}_{3}$ & 55 & 80 & 85 \\
\hline
\end{tabular}

positive value of $\Delta S^{\circ}$ points to increasing of the randomness degree at the resin/solution interface during the progress of sorption process. The negative values of $\Delta G^{\circ}$ values confirm the spontaneous nature of the sorption process.

Finally, it can be concluded that

(1) the prepared magnetite-cored resins have advantage toward the filtration process where the magnetite particles impart the magnetic properties to the beads that allow rapid and easy separation of beads by the application of an external magnetic field avoiding some technical problems arising due to using the traditional filter papers,

(2) the magnetite core allows more spreading of the active group on the surface of resin particles that enhance the adsorption efficiency comparing to other nonmagnetite core resins [10],
(3) the prepared resins are recommended as effective adsorbate materials regarding separation of uranium ions from their bearing solutions particularly in the presence of other competitive metal ions.

\section{Conflict of Interests}

The author declares that there is no conflict of interests regarding the publication of this paper.

\section{References}

[1] O. Philippova, A. Barabanova, V. Molchanov, and A. Khokhlov, "Magnetic polymer beads: recent trends and developments in synthetic design and applications," European Polymer Journal, vol. 47, no. 4, pp. 542-559, 2011.

[2] Q. Yuan and R. A. Williams, "Large scale manufacture of magnetic polymer particles using membranes and microfluidic devices," China Particuology, vol. 5, no. 1-2, pp. 26-42, 2007.

[3] C.-Y. Chen, C.-L. Chiang, and P.-C. Huang, "Adsorptions of heavy metal ions by a magnetic chelating resin containing hydroxy and iminodiacetate groups," Separation and Purification Technology, vol. 50, no. 1, pp. 15-21, 2006.

[4] D. Horák, B. Rittich, and A. Španová, "Carboxyl-functionalized magnetic microparticle carrier for isolation and identification of DNA in dairy products," Journal of Magnetism and Magnetic Materials, vol. 311, no. 1, pp. 249-254, 2007.

[5] A. A. Atia, A. M. Donia, and A. E. Shahin, "Studies on the uptake behavior of a magnetic $\mathrm{Co}_{3} \mathrm{O}_{4}$-containing resin for $\mathrm{Ni}(\mathrm{II})$, $\mathrm{Cu}(\mathrm{II})$ and $\mathrm{Hg}(\mathrm{II})$ from their aqueous solutions," Separation and Purification Technology, vol. 46, no. 3, pp. 208-213, 2005.

[6] A. M. Donia, A. A. Atia, H. A. El-Boraey, and D. H. Mabrouk, "Adsorption of $\mathrm{Ag}(\mathrm{I})$ on glycidyl methacrylate $/ N, N^{\prime}$-methylene bis-acrylamide chelating resins with embedded iron oxide," Separation and Purification Technology, vol. 48, no. 3, pp. 281$287,2006$.

[7] A. M. Donia, A. A. Atia, H. A. El-Boraey, and D. H. Mabrouk, "Uptake studies of copper(II) on glycidyl methacrylate chelating resin containing $\mathrm{Fe}_{2} \mathrm{O}_{3}$ particles," Separation and Purification Technology, vol. 49, no. 1, pp. 64-70, 2006.

[8] A. M. Donia, A. A. Atia, and K. Z. Elwakeel, "Selective separation of mercury(II) using magnetic chitosan resin modified with Schiff's base derived from thiourea and glutaraldehyde," Journal of Hazardous Materials, vol. 151, no. 2-3, pp. 372-379, 2008.

[9] K. Z. Elwakeel and A. A. Atia, "Uptake of U(VI) from aqueous media by magnetic Schiff's base chitosan composite," Journal of Cleaner Production, vol. 70, pp. 292-302, 2014.

[10] A. M. Donia, A. A. Atia, E. M. M. Moussa, A. M. El-Sherif, and M. O. Abd El-Magied, "Removal of uranium(VI) from aqueous solutions using glycidyl methacrylate chelating resins," Hydrometallurgy, vol. 95, no. 3-4, pp. 183-189, 2009.

[11] Z. Marczenko, Separation and Spectrophotometric Determination of Elements, Ellis Harwood, Chichester, UK, 1986.

[12] S. A. Sadeek, M. A. El-Sayed, M. M. Amine, and M. O. Abd ElMagied, "A chelating resin containing trihydroxybenzoic acid as the functional group: synthesis and adsorption behavior for Th(IV) and U(VI) ions," Journal of Radioanalytical and Nuclear Chemistry, vol. 299, no. 3, pp. 1299-1306, 2014.

[13] W. Dong and S. C. Brooks, "Determination of the formation constants of ternary complexes of uranyl and carbonate with 
alkaline earth metals $\left(\mathrm{Mg}^{2+}, \mathrm{Ca}^{2+}, \mathrm{Sr}^{2+}\right.$, and $\left.\mathrm{Ba}^{2+}\right)$ using anion exchange method," Environmental Science \& Technology, vol. 40, no. 15, pp. 4689-4695, 2006.

[14] C. Xiong, X. Liu, and C. Yao, "Effect of $\mathrm{pH}$ on sorption for RE(III) and sorption behaviors of Sm(III) by D152 resin," Journal of Rare Earths, vol. 26, no. 6, pp. 851-856, 2008.

[15] A. O. Dada, A. P. Olalekan, A. M. Olatunya, and O. Dada, "Langmuir, Freundlich, Temkin and Dubinin-Radushkevich isotherms studies of equilibrium sorption of $\mathrm{Zn}^{2+}$ unto phosphoric acid modified rice husk," Journal of Applied Chemistry, vol. 3, no. 1, pp. 38-45, 2012.

[16] V. P. Mpofu, J. Addai-Mensah, and J. Ralston, “Temperature influence of nonionic polyethylene oxide and anionic polyacrylamide on flocculation and dewatering behavior of kaolinite dispersions," Journal of Colloid and Interface Science, vol. 271, no. 1, pp. 145-156, 2004.

[17] A. U. Itodo and H. U. Itodo, "Sorption energies estimation using Dubinin-Radushkevich and Temkin adsorption isotherms," Life Science Journal, vol. 7, no. 4, pp. 31-39, 2010.

[18] K. Dev, R. Pathak, and G. N. Rao, "Sorption behaviour of lanthanum(III), neodymium(III), terbium(III), thorium(IV) and uranium(VI) on Amberlite XAD-4 resin functionalized with bicine ligands," Talanta, vol. 48, no. 3, pp. 579-584, 1999.

[19] V. K. Jain, A. Handa, S. S. Sait, P. Shrivastav, and Y. K. Agrawal, "Pre-concentration, separation and trace determination of lanthanum(III), cerium(III), thorium(IV) and uranium(VI) on polymer supported o-vanillinsemicarbazone," Analytica Chimica Acta, vol. 429, no. 2, pp. 237-246, 2001.

[20] M. Nogami, I. M. Ismail, M. Yamaguchi, and K. Suzuki, "Synthesis, characterization and some adsorption properties of TMMA chelating resin," Journal of Solid State Chemistry, vol. 171, no. 1-2, pp. 353-357, 2003.

[21] P. Metilda, K. Sanghamitra, J. M. Gladis, G. R. K. Naidu, and T. Prasada Rao, "Amberlite XAD-4 functionalized with succinic acid for the solid phase extractive preconcentration and separation of uranium(VI)," Talanta, vol. 65, no. 1, pp. 192200, 2005.

[22] D. H. Phillips, B. Gu, D. B. Watson, and C. S. Parmele, "Uranium removal from contaminated groundwater by synthetic resins," Water Research, vol. 42, no. 1-2, pp. 260-268, 2008.

[23] Y. Jung, S. Kim, S.-J. Park, and J. M. Kim, "Application of polymer-modified nanoporous silica to adsorbents of uranyl ions," Colloids and Surfaces A, vol. 313-314, pp. 162-166, 2008.

[24] G. Tian, J. Geng, Y. Jin et al., "Sorption of uranium(VI) using oxime-grafted ordered mesoporous carbon CMK-5," Journal of Hazardous Materials, vol. 190, no. 1-3, pp. 442-450, 2011.

[25] T. S. Anirudhan, J. Nima, and P. L. Divya, "Adsorption and separation behavior of uranium(VI) by 4-vinylpyridine-graftedvinyltriethoxysilane-cellulose ion imprinted polymer," Journal of Environmental Chemical Engineering, vol. 3, no. 2, pp. 12671276, 2015.

[26] N. T. Tavengwa, E. Cukrowska, and L. Chimuka, "Synthesis of bulk ion-imprinted polymers (IIPs) embedded with oleic acid coated $\mathrm{Fe}_{3} \mathrm{O}_{4}$ for selective extraction of hexavalent uranium," Water SA, vol. 40, no. 4, pp. 623-630, 2014.

[27] M. Solgy, M. Taghizadeh, and D. Ghoddocynejad, "Adsorption of uranium(VI) from sulphate solutions using Amberlite IRA402 resin: equilibrium, kinetics and thermodynamics study," Annals of Nuclear Energy, vol. 75, pp. 132-138, 2015.

[28] J. Li, X. Yang, C. Bai et al., "A novel benzimidazolefunctionalized 2-D COF material: synthesis and application as a selective solid-phase extractant for separation of uranium," Journal of Colloid and Interface Science, vol. 437, pp. 211-218, 2015.

[29] N. T. Tavengwa, E. Cukrowska, and L. Chimuka, "Selective adsorption of uranium (VI) on $\mathrm{NaHCO}_{3}$ leached composite $\gamma$-methacryloxypropyltrimethoxysilane coated magnetic ionimprinted polymers prepared by precipitation polymerization," South African Journal of Chemistry, vol. 68, pp. 61-68, 2015. 


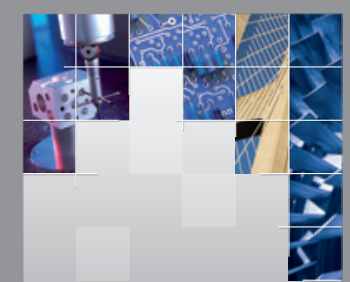

\section{Enfincering}
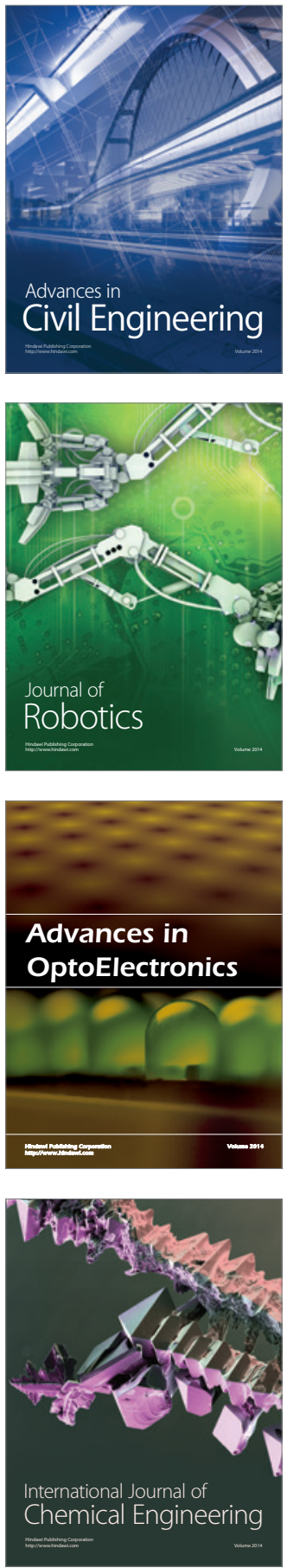

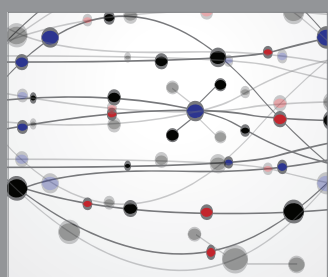

The Scientific World Journal

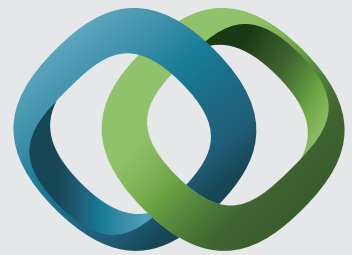

\section{Hindawi}

Submit your manuscripts at

http://www.hindawi.com
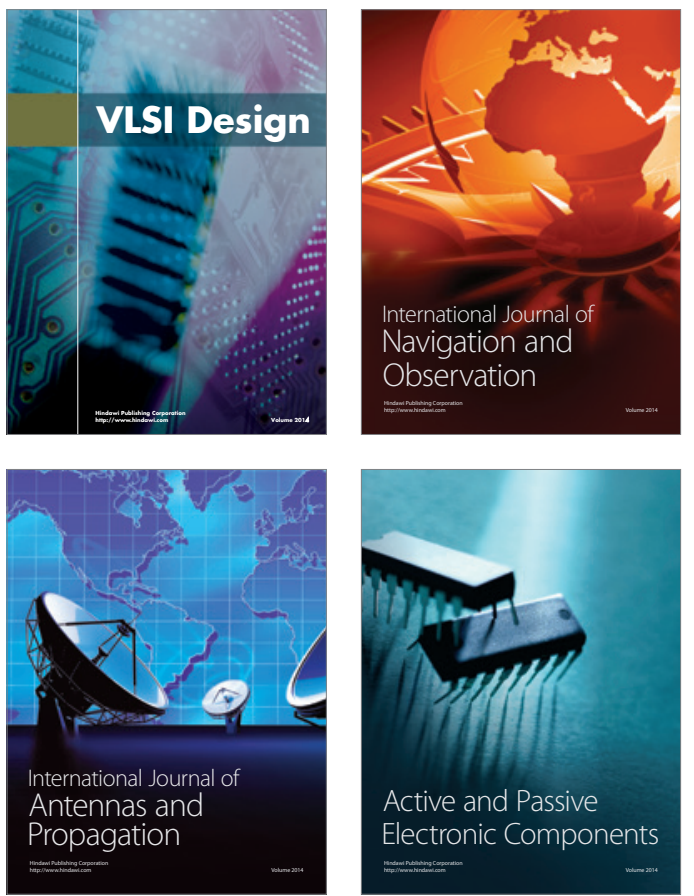
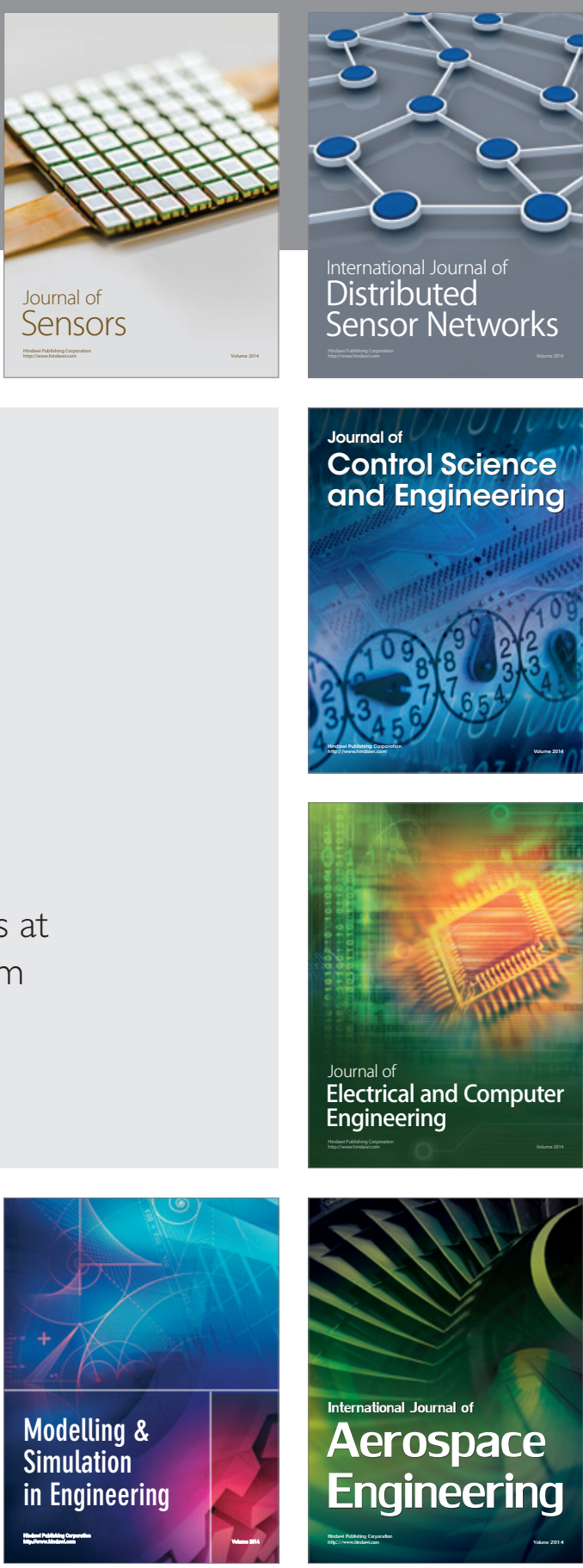

International Journal of

Distributed

Sensor Networks

Journal of

Control Science

and Engineering
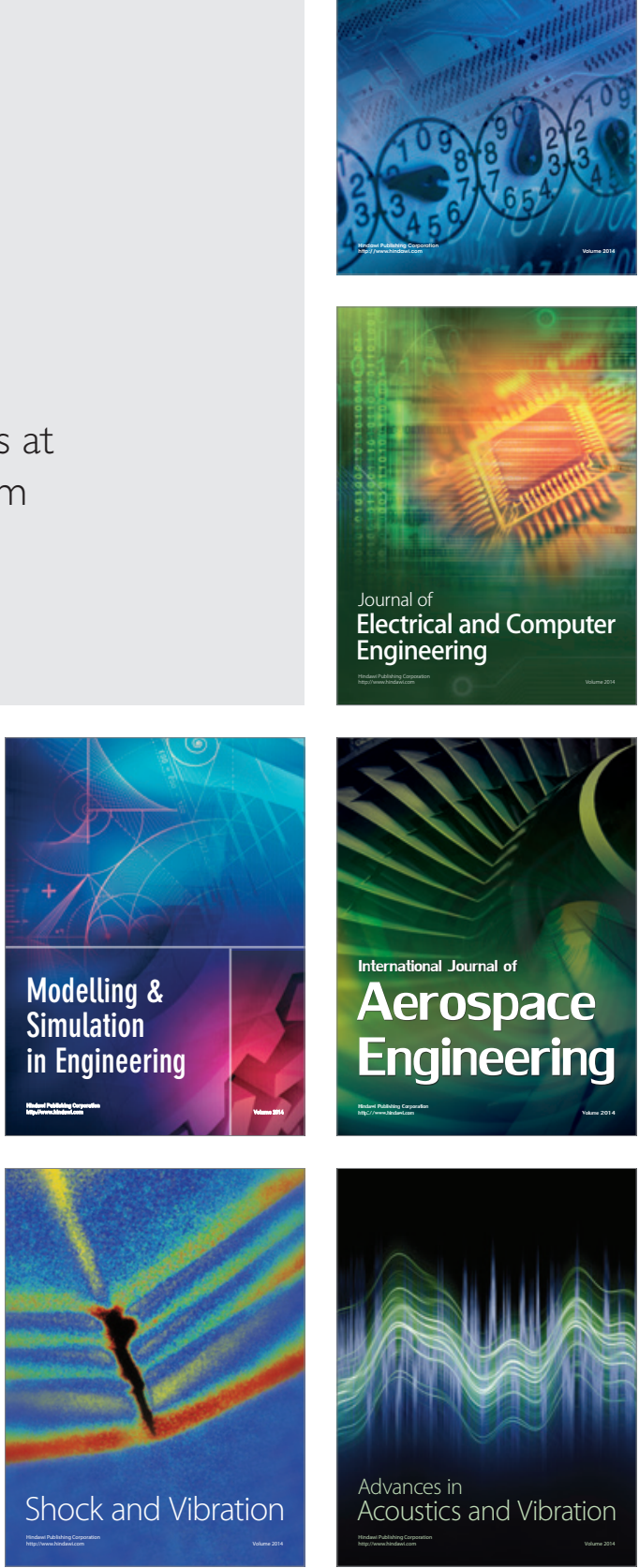